\title{
ANALYSIS OF THE EFFECTS OF IMAGE QUALITY ON DIGITAL MAP GENERATION FROM SATELLITE IMAGES
}

\author{
Hyeon Kim ${ }^{\mathrm{a}}$, Dongwook Kim ${ }^{\mathrm{b}}$, Seungy ong Kim ${ }^{\mathrm{b}}$, Taejung Kim ${ }^{\mathrm{a}, *}$ \\ a Dept. of Geoinformatic Eng., Inha University, Korea - hyeyeon11@inha.edu, tezid@inha.ac.kr \\ ${ }^{\mathrm{b}}$ Geospatial Information Technology Team, Hanjin Information Sy stems \& Telecommunication Co., Ltd -dwkim09@hist.co.kr, \\ sykim00@hist.co.kr
}

Commission IV, Working Group IV/3

KEY WORDS : Image quality, GRD, NIIRS, Accuracy of digital map, High resolution satellite images

\begin{abstract}
:
High resolution satellite images are widely used to produce and update a digital map since they became widely available. It is well known that the accuracy of digital map produced from satellite images is decided largely by the accuracy of geometric modelling. However digital maps are made by a series of photogrammetric workflow. Therefore the accuracy of digital maps are also affected by the quality of satellite images, such as image interpretability. For satellite images, parameters such as Modulation Transfer Function(MTF), Signal to Noise Ratio(SNR) and Ground Sampling Distance(GSD) are used to present images quality. Our previous research stressed that such quality parameters may not represent the quality of image products such as digital maps and that parameters for image interpretability such as Ground Resolved Distance(GRD) and National Imagery Interpretability Rating Scale(NIIRS) need to be considered. In this study, we analy zed the effects of the image quality on accuracy of digital maps produced by satellite images. QuickBird, IKONOS and KOMPSAT-2 imagery were used to analyze as they have similar GSDs. We measured various image quality parameters mentioned above from these images. Then we produced digital maps from the images using a digital photogrammetric workstation. We analyzed the accuracy of the digital maps in terms of their location accuracy and their level of details. Then we compared the correlation between various image quality parameters and the accuracy of digital maps. The results of this study showed that GRD and NIIRS were more critical for map production then GSD, MTF or SNR.
\end{abstract}

\section{INTRODUCTION}

Digital map has to be periodically updated since the geographic information is changing rapidly and it constitutes national geographic information system. To generate and update of digital map, generally, aerial photographs are used. However they have several restrictions for images acquisition and they cannot be acquired over inaccessible areas. For that reason, generation and revision of digital map using satellite images is an issue.

Previous researches investigated that high resolution satellite images can be substituted aerial photograph in cartographic purpose(Konecny and Schiewe, 1996; Fraser, 2002; Kay et al., 2003). They considered the geometric accuracy of satellite image as a key factor to draw such a conclusion. However digital maps are made by a series of photogrammetric workflow. Therefore the accuracy of digital maps are also affected by the quality of satellite images, such as image interpretability. The interpretability of satellite images are expressed by many parameters such as GSD(Ground Sampling Distance), SNR(Signal to Noise Ratio), GRD(Ground Resolving Distance) and NIIRS(National Imagery Interpretability Rating Scale). In several researches, the accuracy of digital map according to GSD of satellite image was discussed. Some researches generated digital map using SPOT-5 identified the number of plotted features(Priebbenow and Clerici, 1998) or compared with respect to features shape and size(Amitabh et al., 2008).

GSD, which used for spatial resolution of satellite images, indicates topographic distance per each pixel but it is not sufficiently to describe image interpretability. On the other hands, GRD and NIIRS are representative parameters for image interpretability. GRD means the smallest size of the object that should be able to discern within images and NIIRS is defined the type of object that should be able to identify. Therefore, in this study, we will consider these parameters for analysis of the effects of image quality on digital map generation from satellite images.

In this paper, QuickBird, IKONOS and KOMPSAT-2, which have similar spatial resolution are used for generation of 1:5000 digital maps. First we estimate quality of each images and generate digital map using digital photogrammetric workstations

\footnotetext{
* Corresponding author: Taejung Kim (tezid@inha.ac.kr)
} 
according to the mapping guidelines of the Korea National Geographic Information Institute(NGII). Then we compare plotted features of each image and reference data, analyze the relation between the number of plotted features and image quality. The result of experiments will be able to show critical parameters of image quality on digital map generation.

\section{DATASETS AND STUDY AREA}

In this experiments, high resolution satellite images, QuickBird, IKONOS and KOMPSAT-2, were used. The study area was over Daejeon, Korea. The area included major layers of 1:5000 digital map feature catalogues such as railroad, river, road, building, type of ground, facilities and topography. Figure 1, 2 and 3 shows QuickBird, IKONOS and KOMPSAT-2 stereo pair over Daejeon, Korea, and Table 1, 2 and 3 indicate their properties.
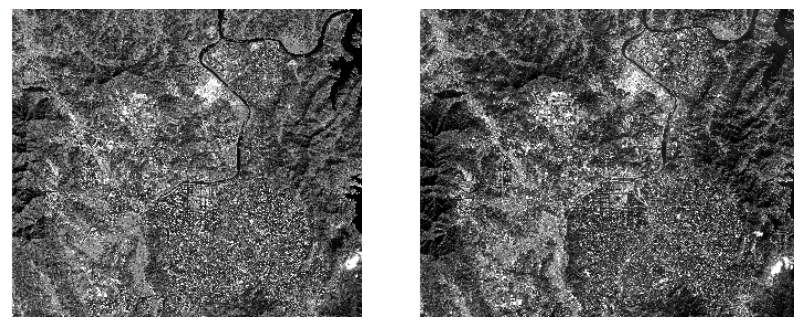

Figure 1. QuickBird stereo pair over Daejeon, Korea

Table 1. The properties of the used QuickBird stereo pair.

\begin{tabular}{|c|c|c|}
\hline \hline & Left & Right \\
\hline Sensor & \multicolumn{2}{|c|}{ QuickBird } \\
\hline Date of acquisition & \multicolumn{2}{|c|}{ 15 Jan 2005 } \\
\hline GSD X(m) & 0.793 & 0.829 \\
\hline GSD Y(m) & 0.711 & 0.708 \\
\hline No.GCP & 22 & 22 \\
\hline \hline
\end{tabular}
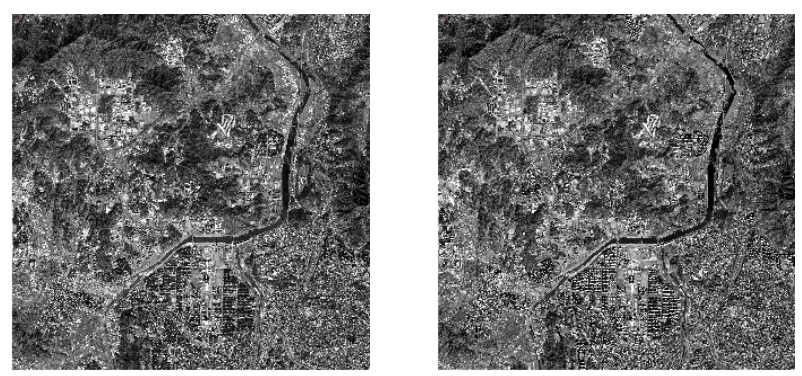

Figure 2. IKONOS stereo pair over Daejeon, Korea

Table 2. The properties of the used IKONOS stereo pair.

\begin{tabular}{|c|c|c|}
\hline \hline & Left & Right \\
\hline Sensor & \multicolumn{2}{|c|}{ IKONOS-2 } \\
\hline Date of acquisition & \multicolumn{2}{|c|}{ 7 Jul 2002 } \\
\hline GSD X(m) & 0.900 & 0.920 \\
\hline GSD Y(m) & 0.960 & 0.900 \\
\hline No.GCP & 10 & 10 \\
\hline \hline
\end{tabular}
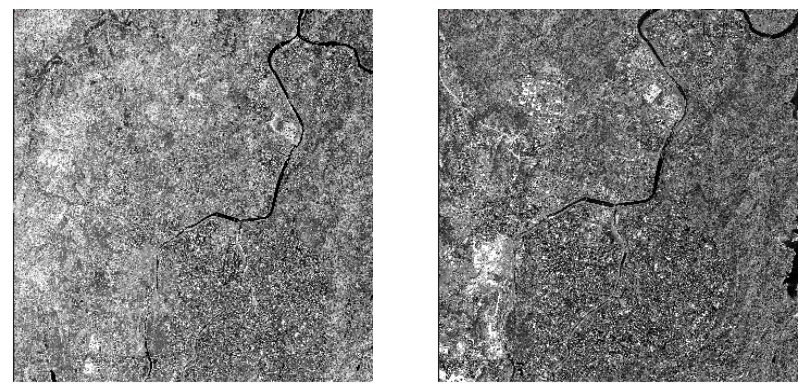

Figure 3. KOMPSAT-2 stereo pair over Daejeon, Korea

Table 3. The properties of the used KOMPSAT-2 stereo pair.

\begin{tabular}{|c|c|c|}
\hline \hline & Left & Right \\
\hline Sensor & \multicolumn{2}{|c|}{ KOMPSAT-2 } \\
\hline Date of acquisition & \multicolumn{2}{|c|}{10 May 2007 } \\
\hline GSD X(m) & 1.295 & 1.042 \\
\hline GSD Y(m) & 1.095 & 1.013 \\
\hline No.GCP & 16 & 16 \\
\hline \hline
\end{tabular}

\section{METHODOLOGY}

\section{Estimation of Image Quality}

The image quality parameters such as RER(Relative Edge Response), GSD, SNR, GRD and NIIRS are used widely. As mentioned above, however, GSD does not reflected image interpretability sufficiently. SNR, which tells the amount of noise of images, is not appropriate to explain the overall quality of image since it can only describe specific aspects of the image quality. Thus it is issued to use RER, GRD and NIIRS that indicate image interpretability. RER is estimated as the difference of edge response at -0.5 pixel and +0.5 pixel from the center of edge. GRD and NIIRS are determined by equations including image quality parameters that estimated by edge analysis method. The artificial targets that is needed for edge analysis have some problems such as high cost to set up. For these reasons, our previous researches performed to estimate GRD and NIIRS using natural targets and validated for reliability of results(Kim et al., 2010; Kim and Kim, 2011).

In this experiment, we measured RER, SNR, GRD and NIIRS using edge analysis method based on natural targets. NIIRS is estimated by two versions with different coefficients.

\section{Generation of 1:5000 Scale Digital Map}

According to the guidelines of NGII, digital map scaled by 1:5000 is composed of 587 geographic feature layers and this study area includes 95 layers of these layers. Also, layers dependant to image acquisition time, required field survey, reference data and additional editing were excluded because maps were plotted using only digital photogrammetric workstation here. After this process, 33 layers of 95 layers were possible to plot. Figure 4 presents the result of digital map generation using aerial photograph over study area. This map was used as the 
reference map. For the generation of digital map, we used SOCET-SET 5.2 and HIST-DPW. The digital map scaled by 1:5000 is generated by professional operator, who had over ten year experience in plotting.

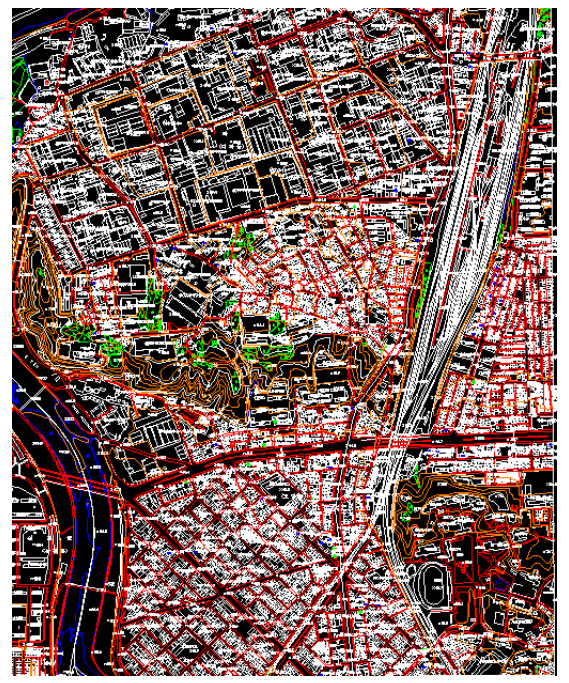

Figure 4. The reference digital map generated by aerial photo over study area.

\section{RESULT AND DISCUSSIONS}

In this study, we carried out image quality estimation by edge analysis method based on natural target. The result of image quality estimation presents that quality of QuickBird image is the best among other images. The difference of GSD between QuickBird, IKONOS and KOMPSAT-2 were not much but difference of other parameters such as RER, GRD, NIIRS were so. QuickBird and IKONOS produced similar values of RER, GRD and NIIRS. On the other hands, the quality of KOMPSAT-2 images was lower in this experiment. Table 4 shows the result of image quality estimation and the number of points used for edge analy sis.

After estimating the image quality, we generated the digital maps scaled by 1:5000. The result of the plotted features is presented in Table 5. In the table, we can identify that digital maps generated from QuickBird and IKONOS present 33layers of 34 layers. The digital map, generated from KOMPSAT-2 satellite images, presents 11 layers of 34 layers. These results imply that identifiable features cannot be expected with GSD only. For all three image types, GSDs were in a similar range. We could also observe that SNR can neither explain the digital map quality. SNR values for all three types were similar.

The image interpretability affected to recognize the features within image. The differences of RER, GRD and NIIRS were significant between QuickBird/ IKONOS and KOMPSAT-2 images.

Table 5. The result of digital map generation(I: Identified, -: Cannot identified)

\begin{tabular}{|c|c|c|c|c|}
\hline \multicolumn{2}{|c|}{ Layer } & \multirow{2}{*}{$\begin{array}{c}\text { Quick } \\
\text { Bird }\end{array}$} & \multirow{2}{*}{$\begin{array}{c}\text { IKO } \\
\text { NOS } \\
\text { I } \\
\end{array}$} & \multirow{2}{*}{$\begin{array}{c}\text { KOM } \\
\text { PSA } \\
\text { T-2 } \\
- \\
\end{array}$} \\
\hline \multirow{3}{*}{$\begin{array}{l}\text { Rail } \\
\text { way }\end{array}$} & Railway & & & \\
\hline & Railway Bridge & $\mathrm{I}$ & I & - \\
\hline & Bridge & I & I & - \\
\hline \multirow{5}{*}{ River } & River & I & I & I \\
\hline & Stream & I & I & - \\
\hline & Dry stream & I & I & - \\
\hline & Lake/reservoir & I & I & I \\
\hline & Concrete Bank & I & I & - \\
\hline \multirow{9}{*}{ Road } & Road & $\mathrm{I}$ & $\mathrm{I}$ & - \\
\hline & City Road & I & I & I \\
\hline & Road in site & I & I & - \\
\hline & Alley & I & I & - \\
\hline & Median Strip & I & I & - \\
\hline & Pedestrian Overpass & I & I & - \\
\hline & Sidewalk & I & I & - \\
\hline & Concrete Bridge & I & I & I \\
\hline & Overpass & I & I & - \\
\hline \multirow{7}{*}{$\begin{array}{l}\text { Buil- } \\
\text { ding }\end{array}$} & $\begin{array}{l}\text { Building other than } \\
\text { housing }\end{array}$ & I & I & I \\
\hline & House & I & I & I \\
\hline & Townhouse & $\mathrm{I}$ & I & I \\
\hline & Apartment & I & I & I \\
\hline & Concrete Wall & I & I & - \\
\hline & Hedge & I & I & - \\
\hline & Fence & $\mathrm{I}$ & $\mathrm{I}$ & - \\
\hline \multirow{7}{*}{$\begin{array}{l}\text { Type } \\
\text { of } \\
\text { ground }\end{array}$} & Branch & I & I & - \\
\hline & Farmland & I & I & - \\
\hline & Other farmland & $\mathrm{I}$ & $\mathrm{I}$ & - \\
\hline & Rice Paddy & I & I & - \\
\hline & Field & I & I & - \\
\hline & Orchard & - & - & - \\
\hline & Cemetery & I & I & - \\
\hline $\begin{array}{l}\text { Facili } \\
\text { ties }\end{array}$ & $\begin{array}{l}\text { Other Concrete } \\
\text { Structure }\end{array}$ & I & I & I \\
\hline \multirow{2}{*}{$\begin{array}{l}\text { Geogra } \\
\text { phic }\end{array}$} & Intermediate Contour & I & $\mathrm{I}$ & $\mathrm{I}$ \\
\hline & Index Contour & I & $\mathrm{I}$ & I \\
\hline & Total & 33 & 33 & 11 \\
\hline
\end{tabular}

Table 4 . The result of image quality estimation.

\begin{tabular}{|c|c|c|c|c|c|c|c|c|}
\hline \hline \multicolumn{2}{|c|}{ Sensor } & $\begin{array}{c}\text { GSD } \\
\text { (across / along) }\end{array}$ & RER & SNR & GRD & NIIRS 3.0 & NIIRS 4.0 & $\begin{array}{c}\text { Number of } \\
\text { edge }\end{array}$ \\
\hline \multirow{2}{*}{ QuickBird } & Left & $0.793 / 0.711$ & 0.4920 & 24.66 & 1.2705 & 4.33 & 4.02 & 230 \\
\cline { 2 - 9 } & Right & $0.829 / 0.708$ & 0.4783 & 23.62 & 1.3661 & 4.29 & 3.97 & 233 \\
\hline \multirow{2}{*}{ IKONOS } & Left & $0.900 / 0.960$ & 0.4723 & 22.38 & 1.5667 & 3.98 & 3.69 & 200 \\
\cline { 2 - 9 } & Right & $0.920 / 0.900$ & 0.4448 & 23.54 & 1.6673 & 3.94 & 3.65 & 202 \\
\hline \multirow{2}{*}{ KOMPSAT-2 } & Left & $1.295 / 1.095$ & 0.3315 & 19.75 & 3.3139 & 3.20 & 2.96 & 293 \\
\cline { 2 - 9 } & Right & $1.042 / 1.013$ & 0.3626 & 18.06 & 2.6278 & 3.51 & 3.27 & 317 \\
\hline \hline
\end{tabular}




\section{CONCLUSIONS}

In this paper, we generated the digital maps at 1:5000 scale using three high resolution satellite images for analysis of the effects of image quality on generation digital map, and we compared plotted features between satellite images and aerial photograph. Also image quality was estimated quantitatively and compared these results with the number of plotted features. The results of experiments showed that digital maps generated by various satellite images could produce different results even if they have similar spatial resolution. RER, GRD and NIIRS that tell the image interpretability were critical parameters than GSD for digital map generation.

Main contribution of this study is the investigation of the plotted features extracted by various satellite images and analyze the effect of image quality from the results of plotted maps.

\section{REFERENCES}

Amitabh, B., Krichna, G., Srinivasan, T. P. and Srivastava, P. K., 2008. An integrated approach for topographical mapping from space using Cartosat- 1 and Cartosat-2 imagery. In: The International Archives of the Photogrammetry, Remote Sensing and Spatial Information Sciences, Beijing, China, Vol. XXXVII, Part B4, pp. 1355-1356.

Fiani, M. and Vatore, F., 2000. An experiment of cartography production and updating using satellite images. In: The International Archives of Photogrammetry and Remote Sensing, Amsterdam, Netherlands, Vol. XXXIII, Part B4, pp. 1114-1121.

Fraser, C. S., 2002. Prospects for mapping from high-resolution satellite imagery. Asian Journal of Geoinformatics, 4(1), pp. 310.

Kay, S., Sqruyt, P. and Alexandrou, K., 2003. Geometric quality assessment of orthorectified VHR space image data. Photogrammetry Engineering and Remote Sensing, 69(5), pp. 484-491.

Kim, J., Jeong, J. and Kim, T., 2010. Development of GRD measurement method using natural target in imagery. Korean Jounal of Remote Sensing, 26(5), pp. 527-536.

Kim, J. and Kim, T., 2011. Development of a natural targetbased edge analysis method for NIIRS estimation. Korean Jounal of Remote Sensing, 27(5), pp. 587-599.

Kim, T., Kim, J., Kim, D. and Jeong, J., 2010. Automated image interpretability assessment by edge profile analysis of natural targets. In : Proceedings of American Society for Photogrammetry and Remote Sensing 2010, California, USA, Apr. 26-30, Digitally available on CD.
Konecny, G. and Schiewe, J., 1996. Mapping from digital satellite image data with special reference to MOMS-02, ISPRS Journal of Photogrammetry and Remote Sensing, 51(1996), pp. 173-181.

Ozbalmumcu, M., 2000. Comparison of the results obtained from the aerial photographs and spot stereo images in the production of 1:50000 scaled topographical maps. In: The International Archives of Photogrammetry and Remote Sensing, Amsterdam, Netherlands, Vol. XXXIII, Part B4, pp. 790-799.

Priebbenow, R. and Clerici, E., 1988. Cartographic applications of SPOT imagery. In: The International Archives of the Photogrammetry, Remote Sensing and Spatial Information Sciences, Kyoto, Japan, Vol. XXVII, PartB4, pp. 289-297.

\section{ACKNOWLEDGEMENTS}

The work in the paper is supported by research grant from "Kompsat-3 System Development Project" of Korea Aerospace Research Institute and "the supporting project to educate GIS experts" of Korea Research Institute for Human Settlements. 